\title{
ORIGINAL ARTICLE Differential expression of miR-17 92 identifies BCL2 as a therapeutic target in BCR-ABL-positive B-lineage acute lymphoblastic leukemia
}

\author{
M Scherr ${ }^{1}$, A Elder ${ }^{2,7}$, K Battmer ${ }^{1,7}$, D Barzan ${ }^{1,7}$, S Bomken $^{2,3}$, M Ricke-Hoch $^{4}$, A Schröder ${ }^{5}$, L Venturini ${ }^{1}$, HJ Blair ${ }^{2}, \mathrm{~J} \mathrm{Vormoor}^{2,3}$, \\ O Ottmann ${ }^{6}$, A Ganser ${ }^{1}$, A Pich ${ }^{5}$, D Hilfiker-Kleiner ${ }^{4}$, O Heidenreich ${ }^{2}$ and M Eder ${ }^{1}$
}

\begin{abstract}
Despite advances in allogeneic stem cell transplantation, BCR-ABL-positive acute lymphoblastic leukaemia (ALL) remains a high-risk disease, necessitating the development of novel treatment strategies. As the known oncomir, miR-17 92, is regulated by BCR-ABL fusion in chronic myeloid leukaemia, we investigated its role in BCR-ABL translocated ALL. miR-17 92-encoded miRNAs were significantly less abundant in BCR-ABL-positive as compared to -negative ALL-cells and overexpression of miR-17 19b triggered apoptosis in a BCR-ABL-dependent manner. Stable isotope labelling of amino acids in culture (SILAC) followed by liquid chromatography and mass spectroscopy (LC-MS) identified several apoptosis-related proteins including Bcl2 as potential targets of miR-17 19b. We validated $\mathrm{Bcl} 2$ as a direct target of this miRNA cluster in mice and humans, and, similar to miR-17 $19 \mathrm{~b}$ overexpression, Bcl2-specific RNAi strongly induced apoptosis in BCR-ABL-positive cells. Furthermore, BCR-ABL-positive human ALL cell lines were more sensitive to pharmacological BCL2 inhibition than negative ones. Finally, in a xenograft model using patientderived leukaemic blasts, real-time, in vivo imaging confirmed pharmacological inhibition of BCL2 as a new therapeutic strategy in BCR-ABL-positive ALL. These data demonstrate the role of miR-17 92 in regulation of apoptosis, and identify BCL2 as a therapeutic target of particular relevance in BCR-ABL-positive ALL.
\end{abstract}

Leukemia (2014) 28, 554-565; doi:10.1038/leu.2013.361

Keywords: BCR-ABL; BCL2; acute lymphoblastic leukaemia; miRNA-17-92

\section{INTRODUCTION}

Acute lymphoblastic leukaemia (ALL) is a heterogeneous disease with multiple, prognostically relevant genetic aberrations. In adults, $30-40 \%$ of patients with precursor-B ALL express the $B C R-A B L$ oncogene as the result of the Philadelphia-translocation $t(9 ; 22)(q 34 ; q 11)$ defining a very high-risk profile. ${ }^{1,2}$ The BCR-ABL oncoprotein is a constitutively active tyrosine kinase involved in hematopoietic cell transformation. Inhibition of its enzymatic activity by specific tyrosine kinase inhibitors has substantially improved and fundamentally changed the treatment of chronic myeloid leukaemia and enhanced cure rates in BCR-ABL-positive childhood ALL. ${ }^{3,4}$ However, treatment of adult BCR-ABL-positive ALL remains challenging. The historically poor outcome of $\mathrm{Ph}+$ ALL patients has been substantially improved by combining tyrosine kinase inhibitors with induction and post-remission chemotherapy, resulting in higher remission rates and therefore a greater proportion of patients undergoing allogeneic hematopoietic stem cell transplantation $(\mathrm{SCT}) .^{5-7}$ At present, myeloablative conditioning followed by allogeneic SCT remains the only established curative therapy, with several prospective trials showing an overall survival of $30-65 \% .^{8-10}$ Despite these advances, high transplant-associated mortality and relapse remain considerable obstacles, and the majority of elderly patients are not considered suitable candidates for allogeneic SCT, resulting in a still dismal long-term outcome. ${ }^{6}$ This has not been altered dramatically by the recent availability of more potent second generation tyrosine kinase inhibitors, ${ }^{11}$ and most likely involves mechanisms of resistance distinct from BCR-ABL tyrosine kinase domain mutations. ${ }^{12}$ Therefore, it is important to develop new targeted agents alongside tyrosine kinase inhibitors to improve survival and reduce morbidity in those patients currently able to undergo allogeneic SCT as well as to offer improved pharmacotherapy for patients not suitable for SCT.

miRNAs are a class of small non-coding RNAs involved in posttranscriptional control of gene expression. Upon processing, miRNAs are incorporated in an effector complex RNA induced silencing complex (RISC) which is recruited to at least partially complementary sites in target-gene mRNAs. Individual miRNAs can bind to multiple mRNAs with differential effects on gene expression of multiple targets. We hypothesised that miRNAs may be used to identify potential leukaemia-relevant therapeutic targets if they are

${ }^{1}$ Department of Hematology, Hemostasis, Oncology and Stem Cell Transplantation, Hannover Medical School, Hannover, Germany; ${ }^{2}$ Newcastle Cancer Centre at the Northern Institute for Cancer Research, Newcastle University, Newcastle upon Tyne, UK; ${ }^{3}$ Department of Paediatric and Adolescent Haematology and Oncology, Great North Children's Hospital, Newcastle upon Tyne, UK; ${ }^{4}$ Department of Cardiology and Angiology, Hannover Medical School, Hannover, Germany; ${ }^{5}$ Department of Toxicology, Hannover Medical School, Hannover, Germany and ${ }^{6}$ Department of Hematology/Oncology and Infectious Diseases, J.W. Goethe-University Hospital Frankfurt, Frankfurt, Germany. Correspondence: Professor M Scherr or Professor M Eder, Department of Hematology, Hemostasis, Oncology and Stem Cell Transplantation, Hannover Medical School, Carl-Neuberg Strasse 1, Hannover 30623, Germany. E-mail: M.Scherr@t-online.de or E-mail: Eder.Matthias@mh-hannover.de

or Professor O Heidenreich, Newcastle Cancer Centre at the Northern Institute for Cancer Research, Newcastle University, Paul O'Gorman Building, Framlington Place, Newcastle upon Tyne, NE2 4AD, UK.

E-mail: olaf.heidenreich@ncl.ac.uk

${ }^{7}$ These authors contributed equally to this work.

Received 14 November 2013; accepted 19 November 2013; accepted article preview online 27 November 2013; advance online publication, 20 December 2013 
differentially expressed in tumour cells and if they are linked to disease-relevant phenotypes.

The polycistronic microRNA cluster miR-17 292 encodes miR-17, miR-18a, miR-19a, miR-20a, miR-19b-1 and miR-92-1.. ${ }^{13}$ Notably, miR-17 92-deficient mice suffer significant developmental cardiac defects and lung hypoplasia though interrogation of haematopoiesis identified isolated defects in B-lineage development. ${ }^{14}$ Moreover, we observed a high expression of miR-17 92 in adult heart and in postnatal cardiomyocytes. miR-17 92 has also been strongly implicated in both solid and haematopoietic malignancies. ${ }^{15,16}$ Of these, the first and now best-studied group is the mature B-lymphoid malignancies. ${ }^{17}$

Conditional knockout of the cluster-revealed modulation of apoptosis as the predominant mechanism of action of miR-17 92. ${ }^{18}$ In normal lymphopoiesis, loss of miR-17 92 results in upregulation of $\mathrm{Bim}(\mathrm{Bcl} 2 \mathrm{l} 11)$ and increased apoptosis, inhibiting the pro-B to pre-B transition. ${ }^{14}$ Conversely, moderate overexpression of miR-17 92 causes a reduction in Bim and Pten expression, resulting in lymphoproliferation and autoimmune disease. ${ }^{19}$ Dissection of the miR-17 92 cluster has demonstrated that miR-19 is both necessary and sufficient to abrogate apoptosis, at least in Myc-mediated lymphomagenesis most likely by repression of PTEN and BIM. ${ }^{18,20}$

Based on our previous work in chronic myeloid leukaemia, ${ }^{21}$ we first analysed miR-17 92 expression in ALL and observed a significantly lower expression in ALL as compared to normal CD34 + cells with further reduction in BCR-ABL-positive as compared to -negative ALL cells. We next over-expressed the miR-17 92 derivative miR-17 $\sim 19 \mathrm{~b}$ in an inducible model of BCR-ABL-positive ALL, thereby identifying impaired apoptosis as a key determinant of reduced miR-17 $\sim 92$ function in this disease setting. Quantitative proteome-wide expression analysis and alignment of miR-17 $\sim 19 \mathrm{~b}$ seed regions identified multiple apoptosis regulators as being downregulated by miR-17 $\sim 19 \mathrm{~b}-$ overexpression. From these, $B C L 2$ was validated as a direct target of the miR-17 and miR-18a, and $B C L 2$ knockdown resulted in strong induction of apoptosis in BCR-ABL-positive, but not $B C R-A B L-n e g a t i v e ~ A L L$ cells. Accordingly, BCR-ABL-positive cells also demonstrated a selective sensitivity to the BCL2 inhibitor $A B T-737$ in vitro. Finally, we demonstrated the sensitivity of $B C R-A B L-p o s i t i v e ~ A L L$ to $A B T-737$ in a real-time in vivo validation assay using patient-derived primary ALL cells transduced with luciferase. This study identifies $B C L 2$ as a potential therapeutic target in BCR-ABL-positive ALL.

\section{MATERIALS AND METHODS}

Patient material

BM and PB samples were collected from 13 and 14 newly diagnosed

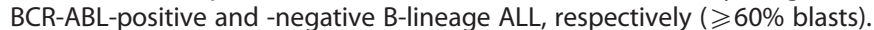
$\mathrm{BM}$-derived CD34 + cells from four healthy volunteers served as controls. The study was approved by the Ethics Committee of the University of Frankfurt.

Patient-derived material used for mouse transplantation was collected as part of the initial diagnostic investigation of patients. It was collected, stored and used with written informed consent according to approvals given by the local institutional review boards and the Declaration of Helsinki. Samples were retrieved from Newcastle Haematological BioBank under the generic BioBank approval given by the Newcastle \& North Tyneside Ethics Committee (REC reference number: 07/H0906/109).

\section{SILAC, LC-MS and data processing}

TonB cells were cultured with either isotopically labelled Lysine $\left({ }^{13} \mathrm{C}_{6}{ }^{-15} \mathrm{~N}_{2}\right.$-Lys) and Arginine $\left({ }^{13} \mathrm{C}_{6}{ }^{-15} \mathrm{~N}_{4}\right.$-Arg) (heavy state), Lysine $\left({ }^{2} \mathrm{H}_{4}\right.$-Lys) and Arginine $\left({ }^{13} \mathrm{C}_{6}\right.$-Arg) (medium state) or natural Lysine and Arginine (light state). Three biological replicates were prepared with all three
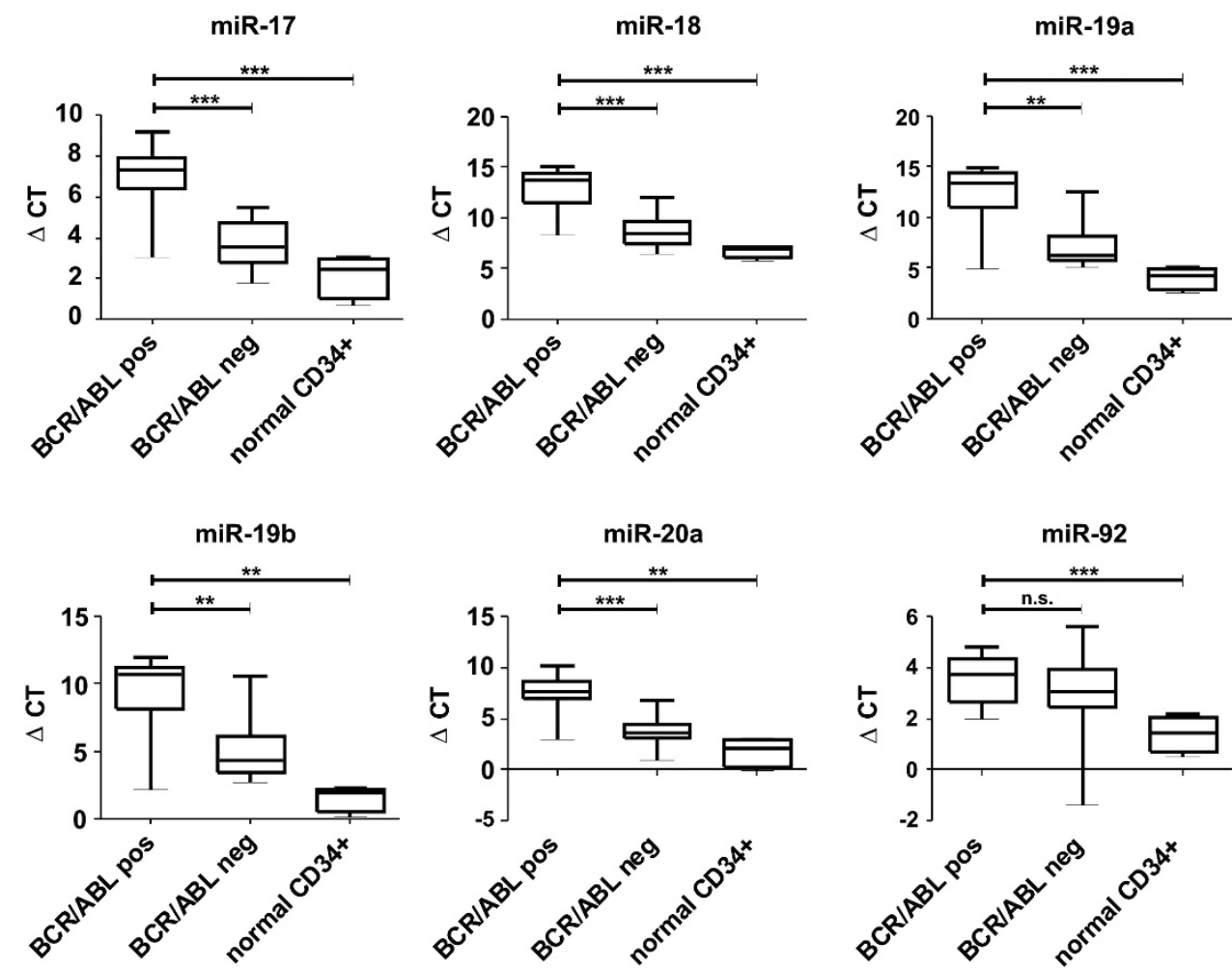

Figure 1. $B C R-A B L+A L L$ samples have a reduced expression of miR-17 92. Differential expression of miR-17 92-encoded miRNAs in primary BCR-ABL-positive and BCR-ABL-negative B-lineage ALL patient samples and normal CD34 + cells as determined by miR-qRT-PCR. Data are presented as $\Delta C T$ of miR-17 $\sim 92$ expression in patient samples, with higher $\Delta C T$ s indicating lower expression. ${ }^{* * P}$-value $<0.001$; ***P-value $<0.0001$. 
labelling states, light, medium and heavy, included as described recently. ${ }^{22}$ Cell lysates were separated by SDS-PAGE followed by gel slicing, extraction and trypsin digestion. Peptide samples were separated and fragmented with a nano-flow ultra-high pressure liquid chromatography system (RSLC, Thermo Scientific, Waltham, MA, USA) coupled online to a Nano Spray Flex Ion Source II (Thermo Scientific) of an LTQ-Orbitrap Velos mass spectrometer. Fragment ion mass spectra were recorded in the LTQ part of the mass spectrometer at a normal scan rate and stored as centroid $\mathrm{m} / \mathrm{z}$ value and intensity pairs. Raw data were processed with the MaxQuant proteomics software (MaxQuant, Martinsried, Germany) suite version
1.1.1.36 for identification and quantification of proteins as described. Peptides and proteins were identified with the implemented Andromeda search engine version 1.1.0.36 and the human entries of the IPI protein data base (v. 3.73).

Immunoprecipitation of human argonaute 2 complexes using the RIP-ChIP kit

Lentiviral supernatants expressing miR-17 $\sim 19 \mathrm{~b}$ and control vector SIEW were used to transduce $\sim 1 \times 10^{6} 293$ cells with an MOI of $\sim 2$.
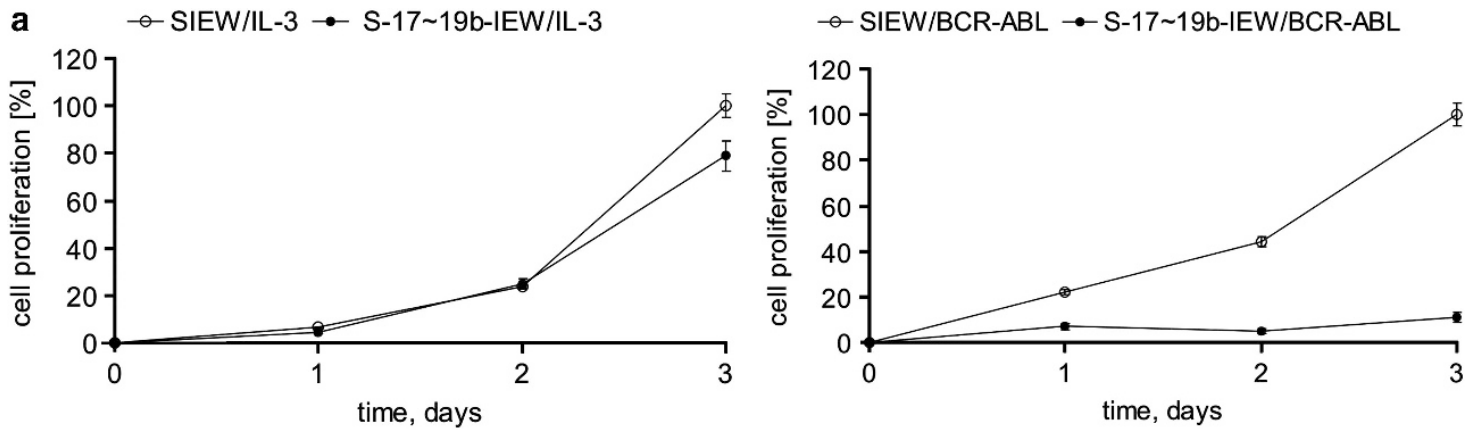

b

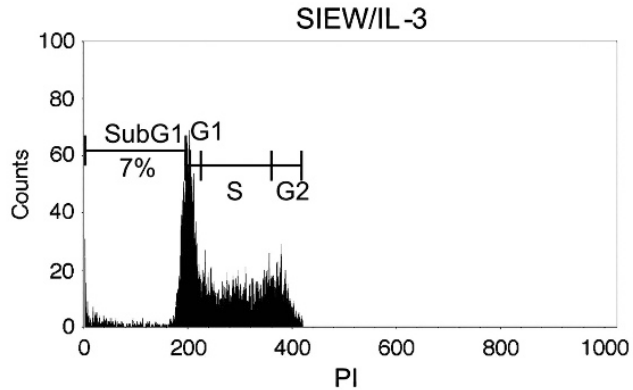

S-miR-17 19b-IEW/IL-3

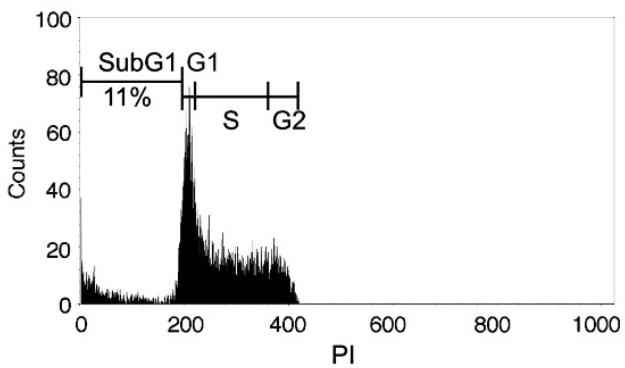

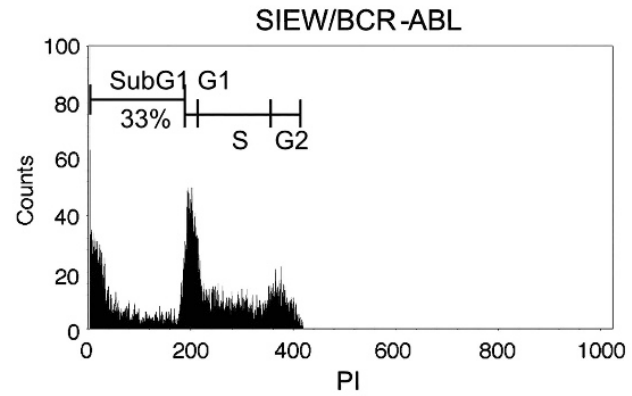

S-miR-17 19b-IEW/BCR-ABL

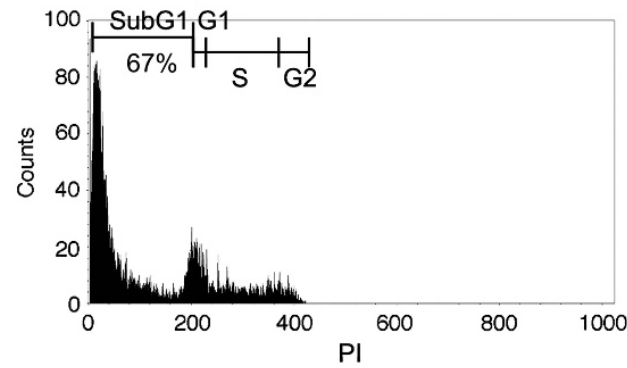

c

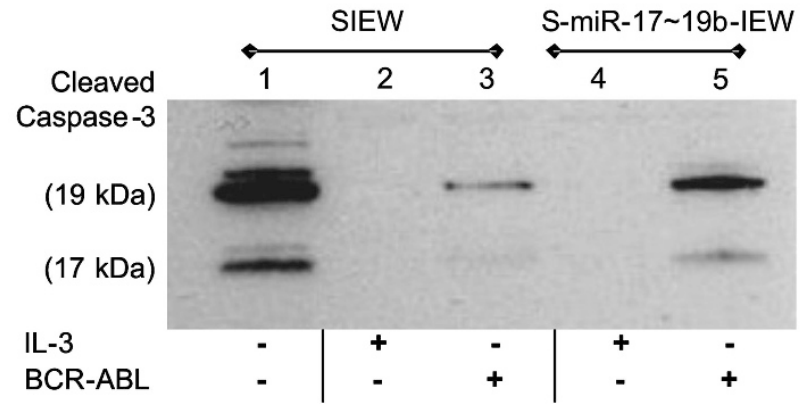

Figure 2. miR-17 $\sim 19 \mathrm{~b}$ reduces proliferation and increases apoptosis in BCR-ABL + cells (a) Proliferation kinetics of TonB cells expressing miR-17 19b either in the presence of IL-3 (left) or doxycycline (right) as determined by trypan blue exclusion. Values are expressed as means \pm s.d. (b) Induction of apoptosis in TonB cells expressing miR-17 19b (lower panels) or control vector SIEW (upper panels) in the presence of IL-3 (left) or doxycycline (right) as determined by PI staining. The percentage of apoptotic cells (subG1 phase) is shown. (c) Cleavage of Caspase 3 in TonB cells expressing control vector SIEW (lanes 1-3) or the miR-17 19b polycistron (lanes 4-5) in the presence of IL-3 (lanes 2 and 4) or doxycycline (lanes 3 and 5). Whole-cell lysates were subjected to western blotting to determine cleavage of caspase 3 $24 \mathrm{~h}$ after induction of BCR-ABL by doxycycline. 
microRNA:mRNA immunoprecipitation was performed using the Magna RIP RNA-Binding Immunoprecipitation kit (Millipore, Billerica, MA, USA) following the manufacturer's protocol. A total of $5 \times 10^{6}$ cells were taken for each replicate and washed in phosphate buffered saline, prior to lysis in $100 \mu \mathrm{l}$ complete RIP-lysis buffer and overnight incubation with magnetic beads conjugated with an anti-AGO2/elF2C2 antibody (Abcam, Cambridge, UK) or control normal mouse $\operatorname{lgG}$ (Millipore) at $10^{\circ} \mathrm{C}$ with rotation. Coimmunoprecipitated RNA, including miRNA:mRNA complexes, was subjected to qRT-PCR and miR-qRT-PCR as described before.

ABT-737 treatment in mouse xenotransplantation studies

Primograft material was lentivirally transduced and intrafemorally transplanted into NSG mice as described previously. ${ }^{23,24}$ Mice were imaged using an IVIS Spectrum pre-clinical imaging system (Perkin Elmer). Mice were injected with either vehicle control or ABT-737 $(50 \mathrm{mg} / \mathrm{kg} /$ day $)$ for a total of 30 days ( 5 days on, 2 days off). Mice were kept until they exhibited clinical symptoms that necessitated humane killing. Kaplan-Meier curves were plotted and analysed using GraphPad Prism software (GraphPad, San Diego, CA, USA), with significance assessed using a Log-rank (Mantel-Cox) test. All work was conducted in accordance with the UK Home Office Project Licence PPL60/3846.

\section{RESULTS}

miR-17 92 is downregulated in BCR-ABL-positive human ALL samples

We previously demonstrated an increased miR-17 $\sim 92$ expression in chronic phase chronic myeloid leukaemia CD34+ cells, compared to normal CD34 + cells from healthy donors. ${ }^{14}$ Based on this, we analysed expression of miR-17 $\sim 92$ encoded miRNAs in $14 \mathrm{BCR}-\mathrm{ABL}$-negative and $13 \mathrm{BCR}-\mathrm{ABL}$-positive ALL samples, as well as normal CD34 + cells, using miR-qRT-PCR. To our surprise, all individual miR-17 92 miRNAs were less abundant in ALL as compared to normal CD34 + cells (Figure 1). Furthermore, BCR$A B L$-positive ALL samples exhibited a 9- to 32-fold reduction in miRNA expression compared to BCR-ABL-negative ALL cells, with the exception of miR-92 which was therefore not further analysed.

The miRNA polycistron is differentially expressed and induces apoptosis in a BCR-ABL-specific manner

To investigate whether differential miR-17 92 expression is controlled by $B C R-A B L$, we used an inducible murine model of $\mathrm{BCR}-\mathrm{ABL}$ expression. Ton $\mathrm{B}$ cells are derived from $\mathrm{BaF} 3$, a B-lymphoid

\begin{tabular}{|l|c|c|c|c|}
\hline Protein name & Gene ID ${ }^{1}$ & $\begin{array}{c}\text { miRNA } \\
\text { binding sites } \\
\text { (RNA22) }\end{array}$ & $\begin{array}{c}\text { fold change } \pm \\
\text { standard deviation }{ }^{2}\end{array}$ & p-value $^{3}$ \\
\hline & & & & \\
\hline Granzyme B & 14939 & 2 & $0.169 \pm 0.038$ & $7.01 \mathrm{E}-04$ \\
\hline Adseverin & 20259 & 2 & $0.229 \pm 0.041$ & $9.46 \mathrm{E}-04$ \\
\hline Bcl2 & 12043 & 6 & $0.368 \pm 0.059$ & $2.97 \mathrm{E}-03$ \\
\hline DnaJB6 & 23950 & 4 & $0.546 \pm 0.142$ & $3.13 \mathrm{E}-02$ \\
\hline AIF & 26926 & 2 & $0.565 \pm 0.022$ & $9.26 \mathrm{E}-04$ \\
\hline Sequestosome 1 & 18412 & 2 & $0.573 \pm 0.071$ & $7.54 \mathrm{E}-02$ \\
\hline Sialophorin & 20737 & 2 & $0.580 \pm 0.106$ & $2.05 \mathrm{E}-02$ \\
\hline SHP-1 & 15170 & 3 & $0.587 \pm 0.052$ & $5.32 \mathrm{E}-03$ \\
\hline
\end{tabular}

b

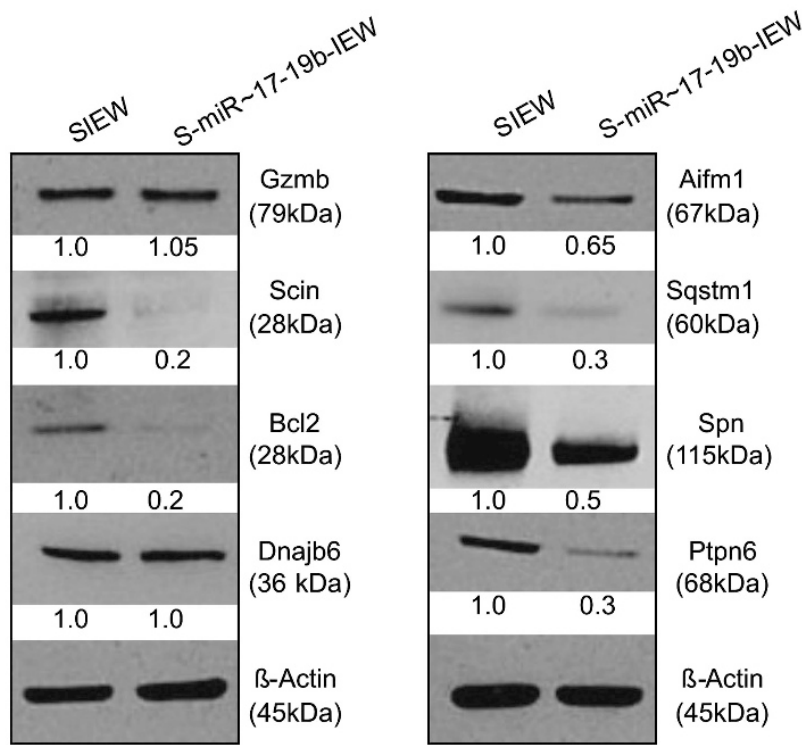

Figure 3. miR-17 19b targets several apoptosis-related proteins. (a) Downregulated proteins involved in the regulation of apoptosis. Reduced protein expression (bold) was validated by immunoblotting as shown in (b). ${ }^{\top}$ Gene ID according to NCBI (http://www.ncbi.nlm.nih.gov/); ${ }^{2}$ mean value of $n=3$ experiments, ${ }^{*} n=2$ experiments; ${ }^{3}$-test; two-tailed; paired. (b) Western blotting showing Granzyme B (Gzmb), Adseverin (Scin), Bcl2, DnaJB6, Aif (Aifm-1), Sequestosome-1 (Sqstm1), Sialophorin (Spn) and Shp-1 (Ptpn6) protein expression in TonB cells lentivirally transduced with control vector SIEW (left) or miR-17 19b (right). Relative expression levels were normalised to $\beta$-actin, which served as a loading control. 
cell line, and have been modified to conditionally express BCR-ABL upon addition of doxycycline. ${ }^{25}$ In this setting, expression of BCR-ABL was associated with a 2.3-3.3-fold reduction in expression of miR-17, $-18 \mathrm{a}$ and $-19 \mathrm{a}$, in agreement with our findings in primary ALL samples (Supplementary Figure 1). These results suggested that miR-17 $\sim 92$ miRNAs could have previously undiscovered anti-oncogenic functions under certain circumstances.

TonB cells are dependent on interleukin-3 (IL-3) for survival and growth; induction of BCR-ABL allows cytokine-independent proliferation, making them an ideal system to study miR-17 92 function in the context of BCR-ABL. As miR-92a expression was unchanged between BCR-ABL-positive and -negative ALL cells (Figure 1), we transduced TonB cells to overexpress miR-17 $\sim 19 \mathrm{~b}$ a derivative of miR-17 92 suitable for transgenic expression. ${ }^{21,26}$ miRNA expression was increased between 5- and 16-fold upon transduction (miR-17 5.2-fold, miR-18a 2.1-fold, miR-19a 9-fold, miR-19b 10.6-fold, and miR-20a 15.8-fold). Proliferation of TonB cells grown in the presence of IL-3 was only slightly reduced by transgenic miR-17 $\sim 19 \mathrm{~b}$ expression as compared to controls (SIEW) (Figure 2a, left). In contrast, BCR-ABL-mediated cell proliferation was strongly inhibited by miR-17 $\sim 19 \mathrm{~b}$ (Figure $2 \mathrm{a}$ right).

To study the impact of miR-17 $\sim 19 \mathrm{~b}$ on cell cycle regulation and apoptosis, transgenic TonB cells were analysed for DNA content in the presence and absence of BCR-ABL. Whereas cell cycling was only marginally affected, apoptosis was markedly enhanced by overexpression of miR-17 $\sim 19 b$ following induction of BCR-ABL. Transgenic expression of miR-17 19b increased the subG1 fraction from 33 to $67 \%$ compared to vector controls (Figure $2 b$, right), whereas in BCR-ABL-negative cells it remained almost unchanged (7 and $11 \%$, respectively, Figure $2 \mathrm{~b}$, left). In agreement with the DNA content analysis, increased cleavage of caspase 3 was observed in BCR-ABL expressing as compared to IL-3 supplemented cell cultures (Figure 2c, lanes 2 and 3). Overexpression of miR-17 $\sim 19 \mathrm{~b}$ also led to a further increase in caspase 3 cleavage in BCR-ABL expressing cells (Figure $2 c$, lanes 3 and 5), but not in cells grown in the presence of IL-3 (Figure 2c, lanes 2 and 4). Together, these data demonstrate that miR$17 \sim 19 \mathrm{~b}$ decreases cell proliferation and markedly increases apoptosis in a BCR-ABL-specific manner.
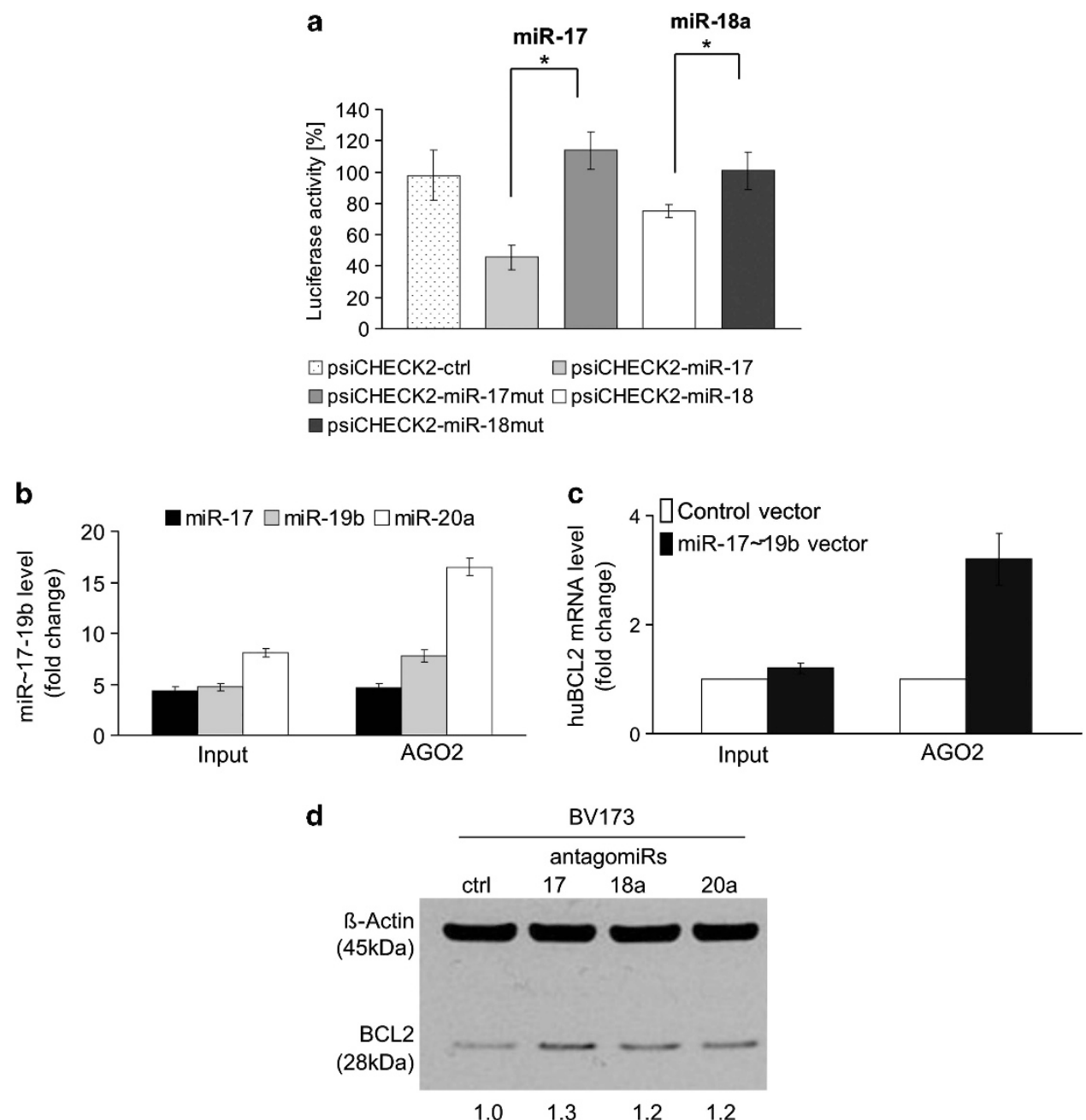

Figure 4. miR-17 19b directly targets BCL2. (a) Bar graph of luciferase activity in stably transfected NIH3T3/S-17-19b-IEW cells co-transfected with a psiCHECK empty vector (psiCHECK-ctrl) or psiCHECK vector harbouring either the candidate wildtype or mutated (mut) miR-17 or miR18a-binding sites in the murine $\mathrm{Bcl} 2$ transcript. ${ }^{*} P$-value $<0.05$. (b and $\left.\mathbf{c}\right)$ RNA-binding protein immunoprecipitation (RIP) assays for AGO2 complexes in 293 cells transduced with lentiviral vectors encoding miR-17 $19 \mathrm{~b}$ or control vector SIEW. Levels of miR-17, miR-18a and miR20a (b) and BCL2 mRNA (c) were quantified by qRT-PCR. Graphs show expression levels in miR-17 19b transduced cells relative to untransduced cells for both the input (left) and AGO2 immunoprecipitated fraction (right). All data are means \pm s.d. ( $n=3$ ). (d) Western blots depicting protein levels of BCL2 after lentiviral transduction of BV173 cells with antagomirs directed against miR-17, miR-18a, miR-20a, or control miR alone. 
miR-17 19b targets regulators of apoptosis

Given that miR-17 $\sim 19 \mathrm{~b}$ overexpression was a driver of cell death in TonB cells in a BCR-ABL-specific manner, we hypothesised that identifying key targets of the cluster could provide novel therapeutic opportunities in BCR-ABL-positive ALL. miRNAs predominantly affect protein expression, so we initially used a stable isotope labelling in cell culture (SILAC)-based approach to identify miR-17 $\sim 19 b-$ and miR-20a-regulated proteins. miR-20a overexpression showed similar, but weaker, effects to miR-17 19b in preliminary experiments (data not shown). TonB cells metabolically labelled with heavy, medium, or light isotope lysine and arginine versions were lentivirally transduced with miR-17 19b, miR-20a, or a control vector (SIEW). Cells were cultured with IL-3 and differential protein expression was analysed by quantitative proteomics using liquid chromatography mass spectrometry (LC-MS). Upon lentiviral transduction, miR-17 $\sim 19 \mathrm{~b}$ miRNA expression was increased between 3- and 12-fold as compared to controls (Supplementary Figure 2A). In total, we identified 3962 proteins from TonB cell lysates and were able to determine the abundance of 3541 of these proteins under all three labelling conditions (Supplementary Table 1A). The correlation between the three labelling conditions was high, with $r^{2}$ between 0.54 and 0.65 (Supplementary Figure 2B). In total, 84 proteins were regulated more than 1.7-fold by miR-17 $\sim 19 b$, with 31 exhibiting higher abundance and 53 exhibiting lower abundance in miR-17 19b transgenic TonB cells. Protein abundance was only slightly affected in miR-20a cells and thus, respective proteins were not further analysed.

We next categorised the 53 low abundance proteins into functional groups using GeneCoDis 2.0. Gene enrichment analysis revealed 269 hits in 102 different gene ontology groups (Supplementary Figure 2C). In keeping with the enriched subG1 fraction and caspase 3 cleavage pattern, 'regulation of apoptosis' (GO: 0042981) contained eight genes (Figure 3a), and was the largest single group of all identified gene ontologies. These findings were confirmed by the KEGG pathway analysis (Supplementary Table 1B). We further validated the apoptosisrelated candidate targets by western blotting. As shown in Figure 3b, protein expression of Adseverin (Scin), Bcl2, Sialophorin (Spn), Aifm-1 (Aif), Sequestosome-1 (Sqstm1) and Shp-1 (Ptpn6) was reduced in the presence of miR-17 $19 \mathrm{~b}$ (from 0.2- to 0.65 -fold), whereas protein levels of Granzyme B (Gzmb) and DnaJB6 remained unchanged.

These data point to a direct role for miR-17 $19 \mathrm{~b}$ encoded miRNAs in the regulation of apoptosis in BCR-ABL-positive ALL. Overcoming apoptosis is key to leukemogenesis, and agents targeting cell death, notably corticosteroids, has a major role in the therapy of ALL. BCL2 is a well-established inhibitor of mitochondrial apoptotic pathways, and has emerged as a potential therapeutic target in both leukaemias and solid tumours. 27,28 We therefore decided to focus on the proteins involved in regulation of apoptosis and on BCL2 in particular.

\section{miR-17 19b suppresses expression of Bcl2}

We next analysed the presence of putative miR-17 $\sim 92$-binding sites (seed matches) within the target mRNAs. As miRNAs binding is not restricted to exact reverse complement seed sequences within the $3^{\prime}$-untranslated region (UTR) ${ }^{28,29}$ we used the miRNA target prediction programme RNA22 based on earlier reports of its low false prediction rate and ability to discover noncanonical targets. ${ }^{29-32}$ As shown in Figure 3a, all targets analysed have at least two miRNA-binding sites for the miR-17 $\sim 19 \mathrm{~b}$ cluster. Notably, six binding sites for miR-17 $\sim 19 \mathrm{~b}$ miRNAs (three sites for miR-18a, two sites for miR-17 and one site for miR-20a) are located within the $5^{\prime}$ UTR and CDS of murine $B C / 2$ (Supplementary Figure $3 A$ ). In human $B C L 2$, we identified 13 binding sites for miR$17 \sim 19 b$ miRNAs (five sites for miR-17, six sites for miR-18a and two sites for miR-20a) located within the CDS and $3^{\prime}$ UTR (Supplementary Figure 3B).

To verify that $B C / 2$ is a direct target of miR-17 $19 \mathrm{~b}$ miRNAs, we transfected luciferase reporter constructs containing murine Bcl2 sequences into miR-17 $\sim 19 \mathrm{~b}$ overexpressing NIH3T3 cells. As shown in Figure 4a, miR-17 $\sim 19 b$ significantly repressed luciferase activity for the wildtype but not for mutated miR-17 and miR-18a-binding sites in the murine Bcl2 $5^{\prime}$ UTR. The CDSbinding sites showed no effect on luciferase activity (data not shown). These data demonstrate that the expression of murine $B C l 2$ is directly regulated by miR-17 $\sim 19 \mathrm{~b}$ through miRNA binding within the $5^{\prime}$-UTR.

Having confirmed murine $B c l 2$ as a target of miR-17 19b, we next analysed specific targeting of the human $B C L 2$ transcript by the cluster. We used qRT-PCR to investigate the association of $B C L 2$ mRNA with AGO2, the catalytic component of RISC in miR-17 19b overexpressing human 293 cells. Assessment of miR-17 19b levels following transduction confirmed overexpression and AGO2 association of all three miRNAs (Figure 4b). Whereas levels of $B C L 2$ mRNA in the input fraction were unchanged following miR-17 $\sim 19 \mathrm{~b}$ overexpression, anti-AGO2 immunoprecipitates specifically pulled down 3.2-fold more $B C L 2$ mRNA as compared to controls (Figure 4c). This shows that miR-17 $\sim 19 \mathrm{~b}$ overexpression results in increased binding of $B C L 2$ mRNA to AGO2 demonstrating specific targeting of BCL2 mRNA by miR-17 $\sim 19 \mathrm{~b}$ miRNAs. We further confirmed this by a complementary approach using lentiviral overexpression of antagomirs against miR-17, miR-18 and miR-20a in the human BCR-ABL-positive BV173 cell line. ${ }^{33}$ All antagomirs increased $B C L 2$ expression by approximately $20 \%$ (Figure 4 d). Together, these data demonstrate direct and functional miRNA binding of miR-17 19b members namely miR-17/miR-20a and miR-18a to human $B C L 2$ mRNA. They also strongly suggested that miR-17 $\sim 19 b$ mediated repression of $B c / 2$ could contribute to the pro-apoptotic effects of the cluster in the context of BCR-ABL.

Repression of murine and human $\mathrm{Bcl} 2$ expression mimics miR$17 \sim 19 \mathrm{~b}$ overexpression

To study the functional contribution of Bcl2 to the miR-17 $\sim 19 \mathrm{~b}-$ induced phenotype, we lentivirally transduced TonB cells to express either anti-Bcl2- or control shRNA. Anti-Bcl2 shRNA reduced $\mathrm{BCl} 2$ protein expression by $\sim 70 \%$ - a similar level to overexpression of $\mathrm{miR}-17 \sim 19 \mathrm{~b}(\sim 80 \%)$ (Figure $5 \mathrm{a}$ ). In IL-3 supplemented cultures, expression of $\mathrm{Bcl} 2$ shRNA inhibited cell proliferation by about $25 \%$ compared to controls (Figure $5 \mathrm{~b}$, left), whereas BCR-ABL driven cell proliferation was inhibited by about $75 \%$ (Figure $5 \mathrm{~b}$, right) suggesting a particular requirement for $\mathrm{BCl} 2$ in BCR-ABL expressing cells.

We next analysed the functional effects of miR-17 $\sim 19 \mathrm{~b}$ overexpression in human BCR-ABL-positive ALL cell lines. As shown in Figure $5 c$, lentiviral transduction of miR-17 $19 \mathrm{~b}$ into the human BCR-ABL-positive cell lines Tom-1, BV173 and SupB15 inhibited cell proliferation by $40-55 \%$ as compared to controls (Figure 5c, left). In contrast, transduction of the BCR-ABL-negative ALL cell lines REH, Nalm-6, and 697 with miR-17 19b had no, or only minor, inhibitory effects on cell proliferation (Figure $5 c$, right). Expression of miR-17 $\sim 19 \mathrm{~b}$ reduced $\mathrm{BCL} 2$ protein expression in BCR-ABL-positive ALL cell lines by $30-70 \%$ (Supplementary Figure 4A).

Cell lines were subsequently transduced with either anti-BCL2 or control shRNA. Anti-BCL2 shRNA substantially reduced $B C L 2$ mRNA expression in all cell lines (Supplementary Figure 4B). In BCR-ABL-positive Tom-1, BV173 and SupB15 cells, expression of $B C L 2$ shRNA inhibited cell proliferation (Figure $5 d$, left), whereas reduction of $B C L 2$ mRNA expression in BCR-ABL-negative Nalm-6, REH and 697 cells did not substantially inhibit cell proliferation. (Figure $5 \mathrm{~d}$, right). Efficient downregulation of $\mathrm{BCL} 2$ protein in 
a
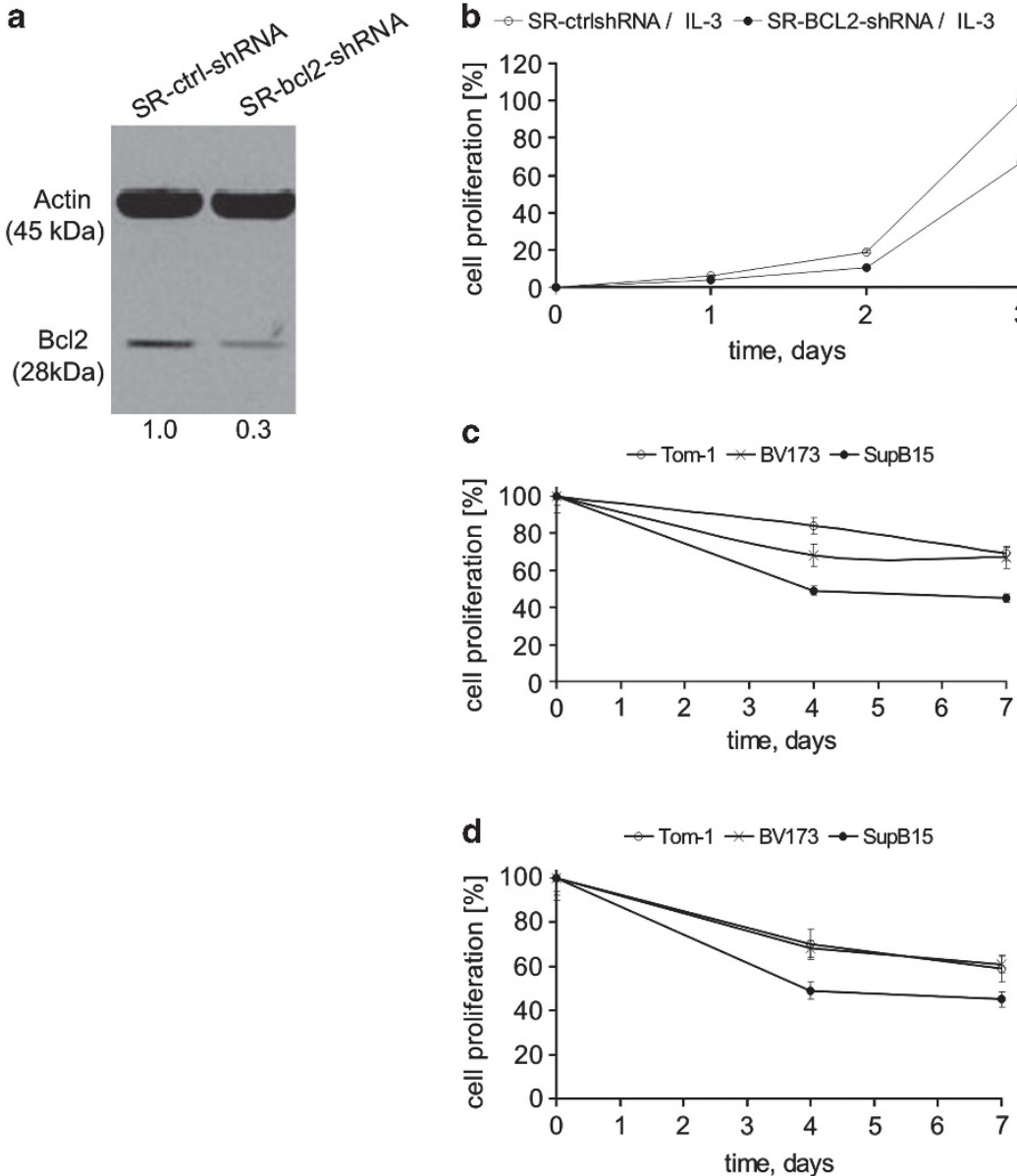

e

SIEW
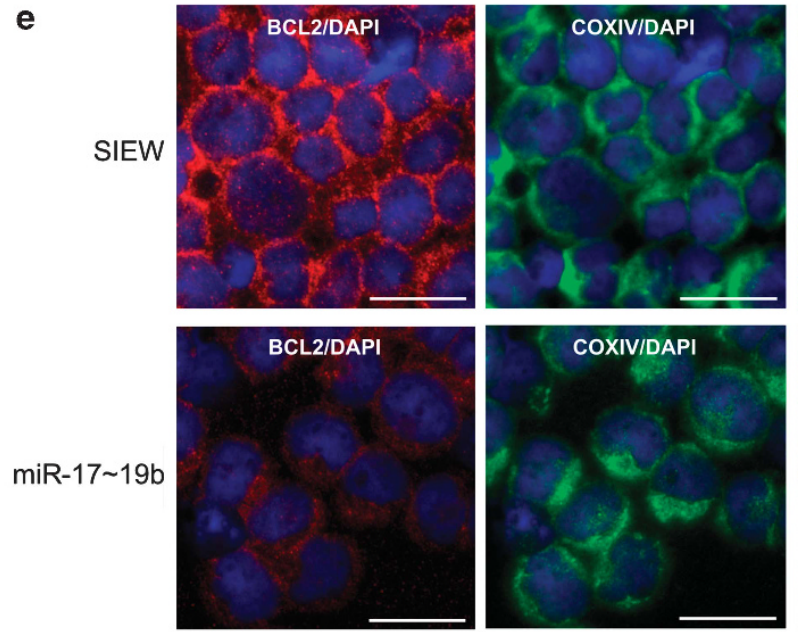

BCL2/DAPI

Bcl2-shRNA

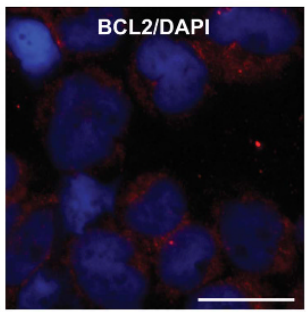

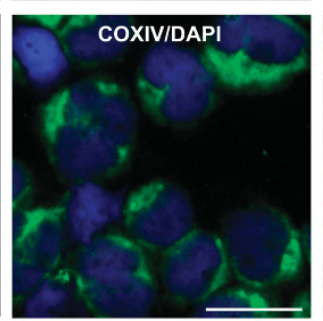
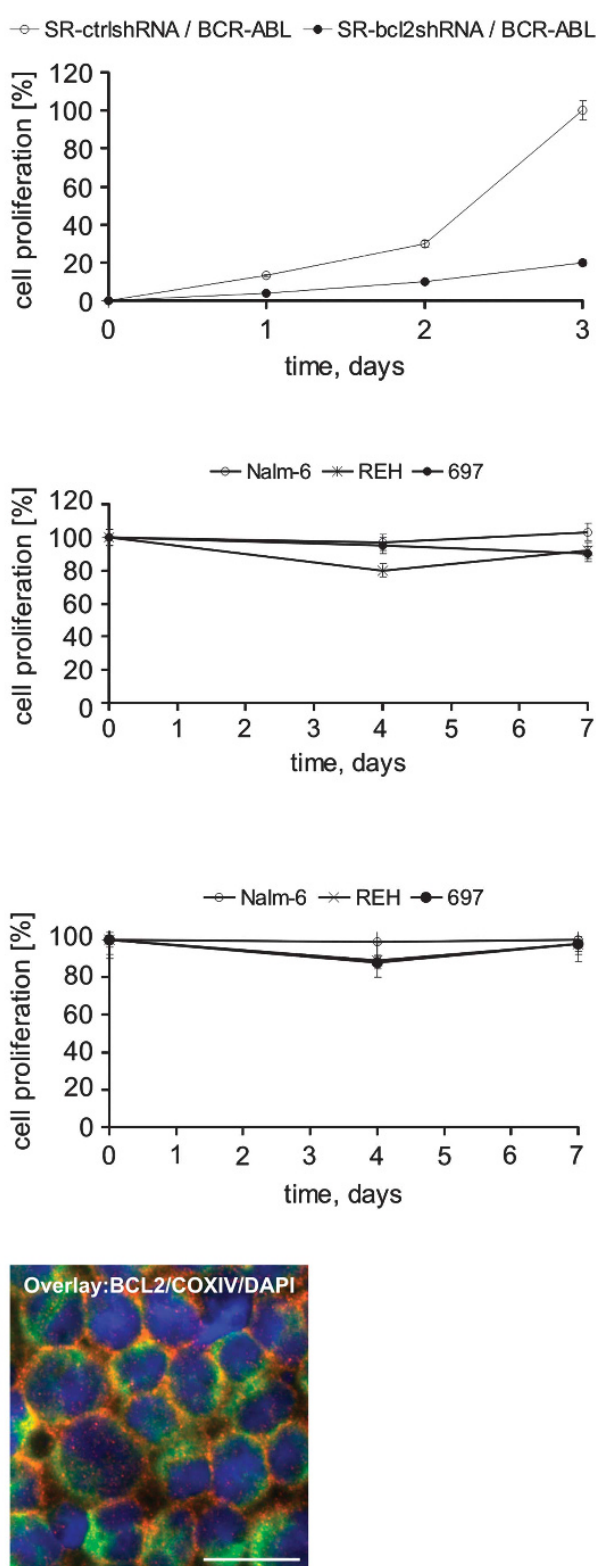

Overlay:BCL2/COXIVIDAPI

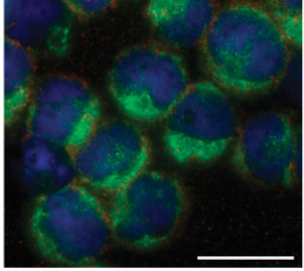

Overlay:BCL2/COXIVIDAPI

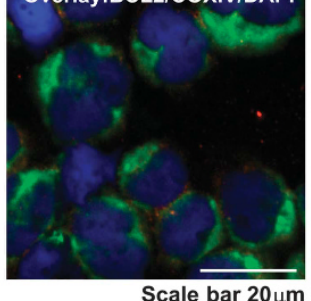


SupB15 cells by lentivirally mediated overexpression of both miR-17 $\sim 19 b$ and anti-BCL2 shRNA was further confirmed by fluorescence microscopy demonstrating co-localisation of BCL2 (red) and the mitochondrial protein COX4 (green) (Figure 5e). Together, these results demonstrate a specific role for BCL2 in the proliferation of human BCR-ABL-positive ALL cells and suggest that the miR-17 92 cluster suppresses BCL2 in BCR-ABL-positive cells.

The BCL2 inhibitor ABT-737 specifically inhibits BCR-ABL-positive lymphoid cell lines

The importance of BCL2 for the proliferation of BCR-ABL-positive cell lines suggested that $B C L 2$ could be a highly promising novel therapeutic target. To assess the potential of pharmacological $B C L 2$ inhibition in $B$-lineage $A L L, B C R-A B L-$ positive and -negative ALL cell lines were treated with the BCL2 inhibitor ABT-737 for $24 \mathrm{~h}$, prior to assessment of cell death. ABT-737 inhibited proliferation of the BCR-ABL-positive cell lines Tom-1, BV173 and SupB15 with $\mathrm{IC}_{50} \mathrm{~S}$ of $0.054 \mu \mathrm{m}, 0.15 \mu \mathrm{m}$ and $0.030 \mu \mathrm{m}$, respectively (Figure 6, left). In contrast, the $I_{50}$ for ABT-737 was substantially higher in two out of three BCR-ABL-negative cell lines 697, Nalm-6 and $\mathrm{REH}$ with $\mathrm{IC}_{50} \mathrm{~S}$ of $0.066 \mu \mathrm{m}, 2.2 \mu \mathrm{m}$, and $7.8 \mu \mathrm{m}$, respectively (Figure 6, right).

Effects of ABT-737 and Imatinib in BCR-ABL-positive ALL cells Having demonstrated specific effects of pharmacological BCL2 inhibition in BCR-ABL-positive cells, we compared ABT-737 with imatinib in both a cell line (BV173) and a patient-derived sample. For the latter, we used primary BCR-ABL-positive precursor-B cell ALL blasts, which had been passaged through NOD/LtSz-scid IL-2R $\gamma$ null (NSG) mice (primograft, designated L4951 cells). ${ }^{23}$ Cells were incubated with either drug or vehicle control and the number of viable cells was determined over time. As shown in Figures 7a and b, ABT-737 induced a more rapid decline of viable cell numbers than imatinib in both BV173 and L4951 cells. Interestingly, immunoblotting revealed a rapid decrease in $\mathrm{BCL} 2$ protein expression following $\mathrm{ABT}-737$ treatment in both primograft material and BV173 cells (Figures 7c and d). A rapid decline of BCL2 protein was also observed in SupB15 cells as early as $6 \mathrm{~h}$ after addition of ABT-737 (Supplementary Figure 5A). Imatinib treatment did not affect the $\mathrm{BCL} 2$ protein expression and this depletion was not observed in BCR-ABL-negative ALL cell lines (Figure 7e). Furthermore, after ABT-737 but not imatinib treatment, a delayed increase in expression of miR-17 92 encoded miRNAs (starting at approximately $24 \mathrm{~h}$ after addition of ABT-737, Figure 7f, Supplementary Figure 5B) has been observed. These data demonstrate different mechanisms of action for ABT-737 and imatinib in BCR-ABL-positive ALL cells and suggest a role for miR-17 92 encoded miRNAs in BCL2-mediated apoptotic pathways in these cells. They also suggest that inhibition of BCL2 by $A B T-737$ results in perturbations in wider signalling networks that leads to expression changes in both miR$17 \sim 92$ and BCL2 protein.

\section{$\mathrm{BCL} 2$ inhibition inhibits tumour xenograft growth in vivo}

Finally, we examined the therapeutic potential of BCL2 inhibition by evaluating the ability of ABT-737 to inhibit growth of primary leukaemia cells in vivo. We developed a murine xenotransplantation assay of patient-derived primary leukaemic cells, which allows for real-time monitoring of drug therapies by bioluminescent imaging. ${ }^{24}$ Primograft L4951 cells were lentivirally transduced with a luciferase-expressing vector (pSLIEW, transduction efficiency $\sim 40 \%)$ and transplanted intrafemorally into NSG mice. Following successful engraftment determined by bioluminescent imaging, mice were injected intraperitoneally with either ABT-737 $(50 \mathrm{mg} / \mathrm{kg} / \mathrm{day})$ or vehicle control for a total of 30 treatments. Mice treated with ABT-737 showed a substantially reduced dissemination of luciferase-expressing leukaemic blast cells over the treatment period, represented by a decrease in total photon flux emitted (Figures $8 a$ and b, Supplementary Figure 6). In addition, ABT-737 treatment significantly lengthened the time before the mice developed clinical symptoms that necessitated humane killing, with median survival increased from 151 to 190 days $(P=0.0004)$ (Figure $8 \mathrm{c}$ ). Termination of ABT-737 treatment was followed by an increase in photon flux, demonstrating that disease control during the treatment period was being mediated by $A B T-737$. These results demonstrate that $B C L 2$ inhibition is a

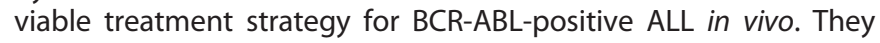
also confirm the potential of our model to assess novel drug therapies on patient-derived malignant cells in an in vivo setting.

\section{DISCUSSION}

In a search for new therapeutic strategies in BCR-ABL-positive ALL, we identified targets of miRNAs with differential expression and function in these cells. As we have shown upregulation of
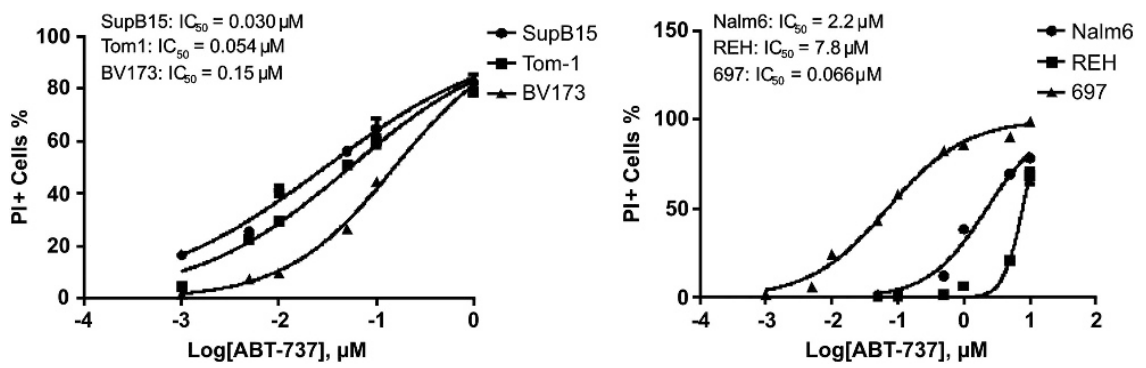

Figure 6. Pharmacological inhibition of $B C L 2$ is effective in $B C R-A B L+$ cell lines. Cell death was assessed by uptake of propidium iodide (PI) after treatment with increasing concentrations of ABT-737 in BCR-ABL-positive cell lines (Tom-1, SupB15, BV173, left) and BCR-ABL-negative cell lines (Nalm-6, REH, 697, right) for $24 \mathrm{~h}$. IC 50 values were calculated using GraphPad Prism software.

Figure 5. Repression of $\mathrm{Bcl} 2$ mimics miR-17 19b overexpression in human and mouse. (a) Western blots of $\mathrm{Bcl} 2$ after lentiviral transduction of TonB cells with anti-Bcl2 shRNA or control shRNA. (b) Proliferation kinetics of TonB cells expressing anti-Bcl2 shRNA or control vector either in the presence of IL-3 (left) or doxycycline (right) as determined by trypan blue exclusion. (c) Proliferation kinetics of BCR-ABL-positive cell lines Tom-1, SupB15, and BV173 (left) and of BCR-ABL-negative cell lines Nalm-6, REH and 697 (right) expressing miR-17 19b or control vector using trypan blue exclusion. (d) Proliferation kinetics of BCR-ABL-positive cell lines Tom-1, SupB15, or BV173 (left) and of BCR-ABL-negative cell lines Nalm-6, REH, or 697 (right) after transduction with anti-BCL2 shRNA or ctrl-shRNA using trypan blue exclusion. All values were expressed as means \pm s.d. (e) Fluorescence microscopy of SupB15 cells transduced with control vector (top), miR-17 19b (middle), or anti-BCL2 shRNA (down) of BCL2 protein (red) or the mitochondrial marker COX IV (green). Cells were counterstained with DAPI (blue), scale bar: $20 \mu$ m. 
a

BV173 cells

$\longrightarrow$ DMSO $\rightarrow$ - Imatinib $\rightarrow$ ABT-737

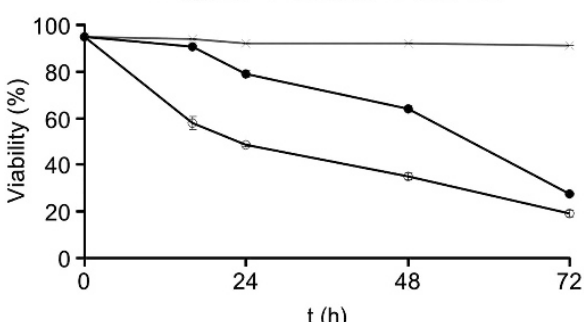

C

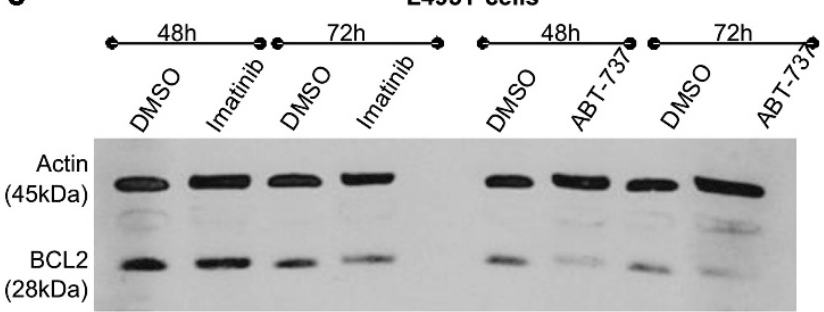

b

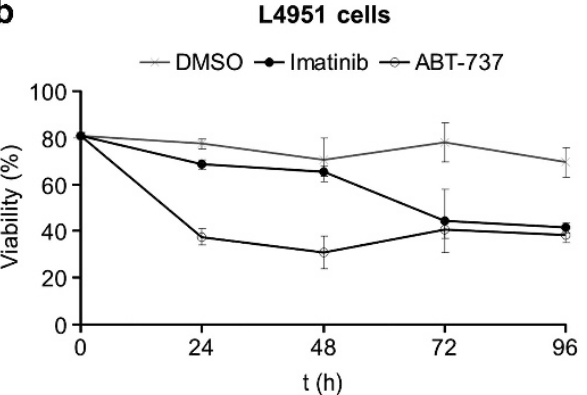

d

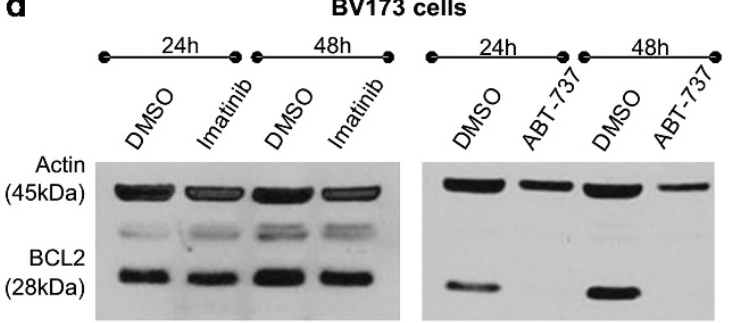

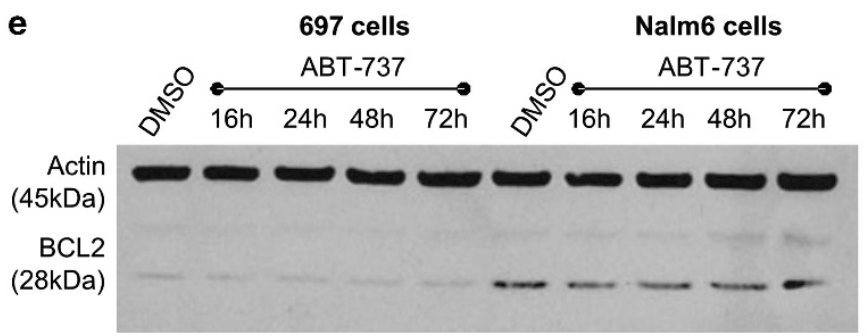

f

L4951 cells
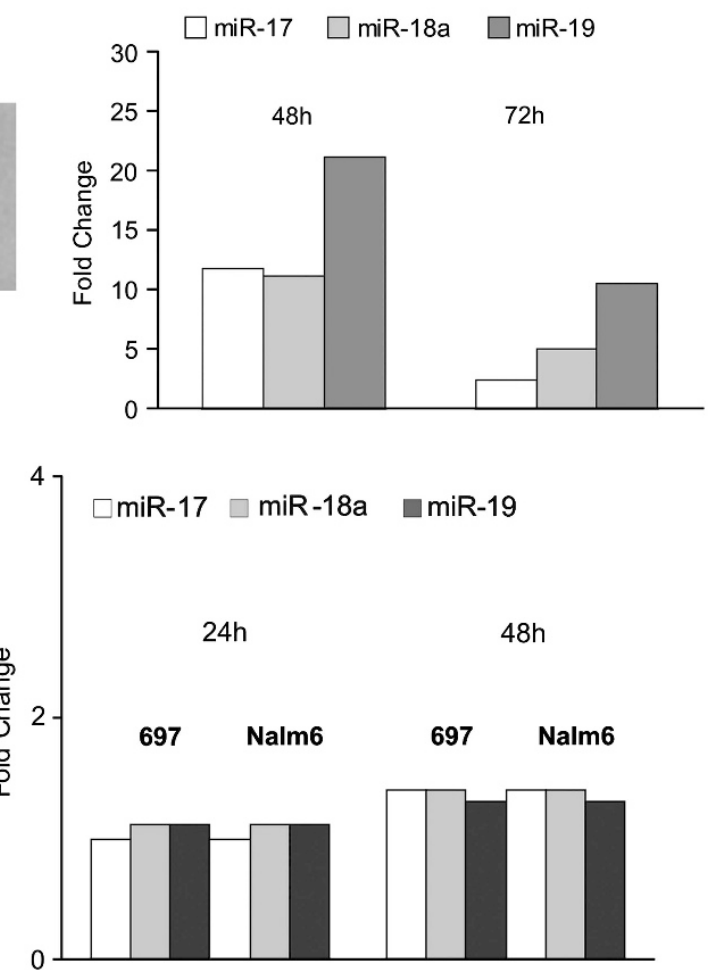

Figure 7. ABT-737 is more potent than Imatinib in cell lines and primary material. BV173 cells (a) and L4951 primograft cells (b) were treated with ABT-737 $(0.1 \mu \mathrm{M})$, Imatinib $(1 \mu \mathrm{M})$ or DMSO control and cell viability was assessed by PI uptake. (c and d) Western blots depicting protein levels of BCL2 in BCR-ABL-positive L4951 and BV173 cells after treatment with Imatinib $(1 \mu \mathrm{M})$ or ABT-737 $(1 \mu \mathrm{M})$ at the indicated time points. (e) Western blots depicting protein levels of BCL2 in BCR-ABL-negative 697 and Nalm- 6 cells after treatment with ABT-737 at indicated time points. (f) The levels of miR-17, miR-18a and miR-19 following ABT-737 treatment were determined by miR-qRT-PCR. Graphs show fold change compared to DMSO controls.

the oncomir miR-17 92 in chronic phase chronic myeloid leukaemia, ${ }^{21}$ we investigated the role of this cluster in BCR-ABLpositive ALL. To our surprise, patient samples showed significantly lower expression of mature miR-17 92 elements in BCR-ABLpositive ALL than in either BCR-ABL-negative ALL or normal CD34 + cells. Furthermore, the TonB model of inducible BCR-ABL expression on a murine B-lymphoid precursor background demonstrated a significant reduction in mature miR-17 92 expression following induction of $B C R-A B L$, confirming the specificity of this finding for BCR-ABL-positive ALL. Overexpression of the miR-17 92 derivative miR-17 $\sim 19 \mathrm{~b}$ resulted in reduced proliferation and notably a substantial proapoptotic effect, with a significantly enriched subG1 population and concomitant cleavage of caspase 3 . This effect is surprising, as 


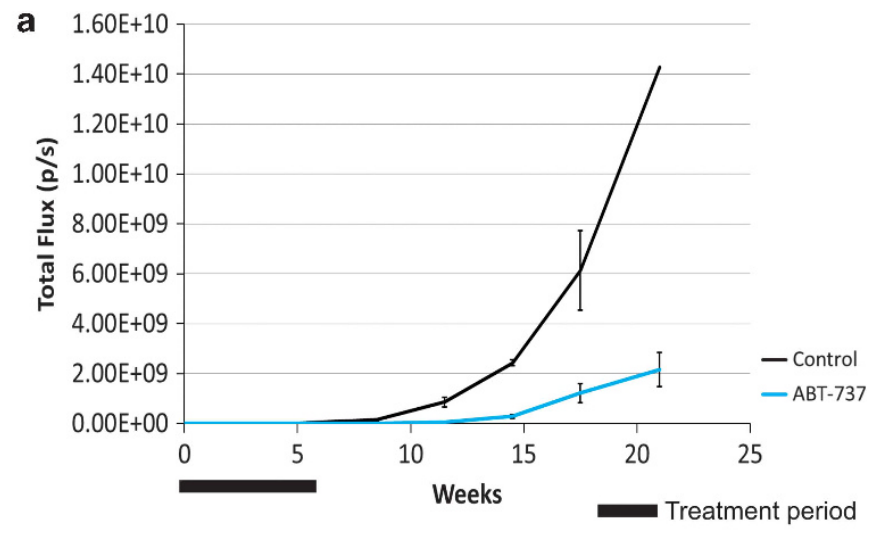

\section{b}
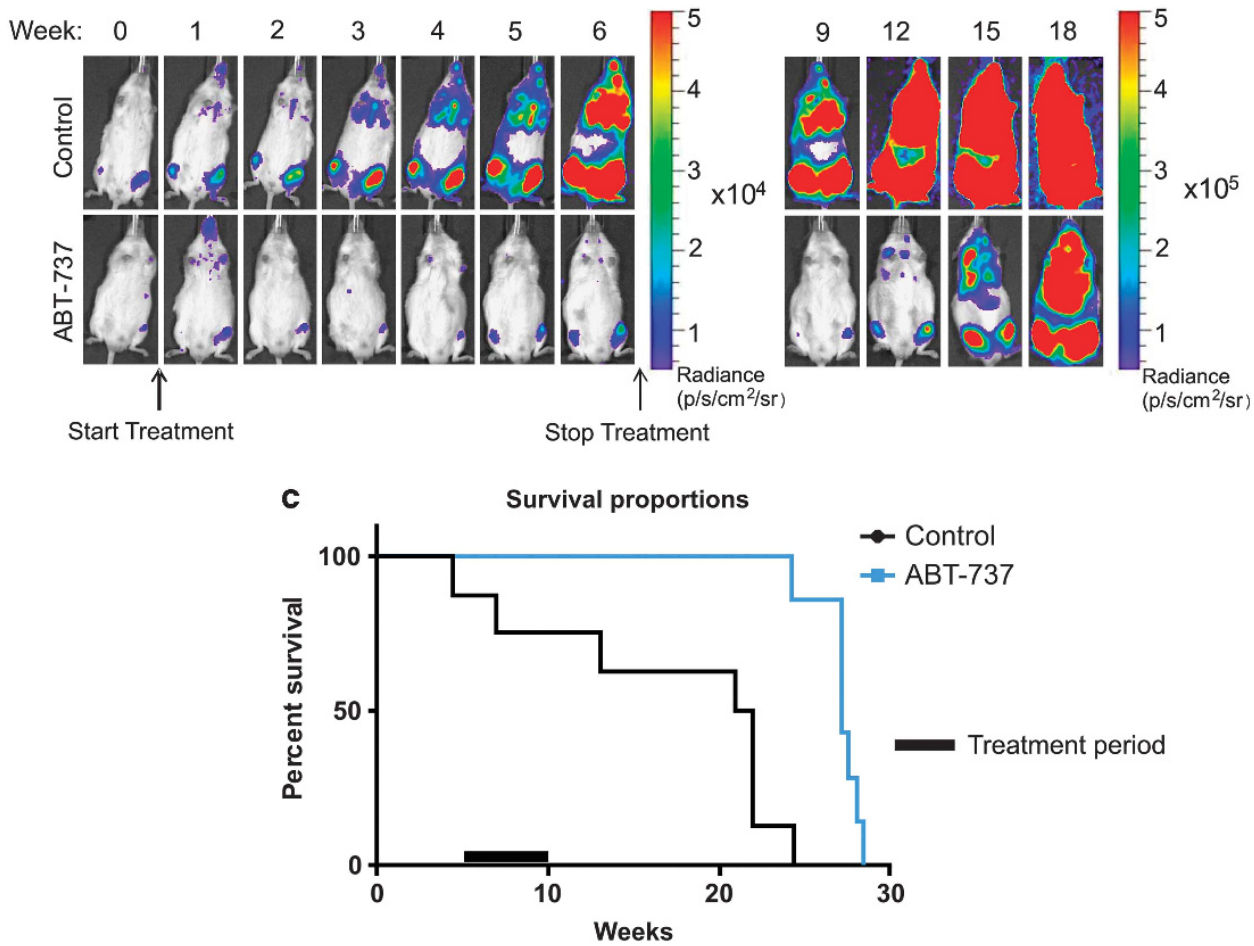

Figure 8. ABT-737 impairs expansion of human primary BCR-ABL + ALL cells in vivo. (a) NSG mice were transplanted with luciferase-expressing L4951 blasts and treated with ABT-737 ( $50 \mathrm{mg} / \mathrm{kg} /$ day) or vehicle control for 6 weeks (black bar) following successful engraftment. Graph shows average of total flux from whole mouse at each measurement point, $n=7$ mice per group. (b) Images of representative mice from ABT-737 treated and control groups showing expansion of luciferase-expressing transduced blasts over time. Mice during treatment period (weeks 0-6) and after treatment (weeks 9-18) are shown on different radiance scales to avoid image saturation. Supplementary Figure 6 shows all the images on the same scale. (c) Kaplan-Meier survival curves for mice transplanted with L4951 blasts treated with ABT-737 (50 mg/kg/day) or vehicle control. Black bar $=$ treatment period. Median survival 151 days (control), 190 days (ABT-737 treated), $P=0.0004$.

previous studies of miR-17 92 have shown direct regulation of 'pro-apoptotic' molecules Bim and Pten in normal lymphopoiesis, ${ }^{14}$ MYC-driven lymphomas ${ }^{18,20}$ and immunodeficiency or lymphoproliferative states. ${ }^{19}$ It is interesting to note that while this effect, in MYC-driven lymphoma at least, is primarily mediated by miR-19 family members (miR-19a/b), we have identified principally a miR-17 family- (miR-17, miR-20a/b, miR-106a/b and miR-93) and miR-18 family(miR-18a/b)-driven effect in BCR-ABL-positive ALL on $B C L 2$, indicating differences in pro- and anti-apoptotic functions of miR-17 92 between the various cellular contexts.

In keeping with the phenotype described for the TonB model, an unbiased global proteomic approach identified several apoptosis-related proteins as miR-17 $\sim 19 \mathrm{~b}$ targets. As targeting the anti-apoptotic pathway offered a logical therapeutic approach, we chose to focus our validation studies on the well-characterized anti-apoptotic protein BCL2. BCL2, an inhibitor of the mitochondrial apoptotic pathway, is the founding member of a large family of $\mathrm{BH}$-domain containing proteins with pro- and anti-apoptotic activities upstream of caspase-activation. ${ }^{34,35}$ Notably, $B C / 2$ induction has previously been shown to be important for prevention of apoptosis in BCR-ABL expressing BaF3 cells. ${ }^{36}$ Our data suggest that downregulation of miR-17 $\sim 92$ may be an important mediator of this effect. This may also explain why overexpression of the cluster has little phenotypic effect in BCR-ABLnegative ALL cells, where $B c 12$ expression may be less critical.

Small molecule BH3-domain mimetica, notably ABT-737 $7^{37}$ and its orally bioavailable analogue ABT-263 (Navitoclax) ${ }^{38}$ have been designed to inhibit BCL2. ${ }^{39}$ BCL2 inhibition has demonstrated efficacy in pre-clinical and early phase clinical trials in small-cell-lung cancer, ${ }^{40}$ myeloma $^{41}$ and high-risk $B$ cell 
non-Hodgkin lymphoma. ${ }^{42}$ Furthermore, dramatic responses have been seen in chronic lymphocytic leukaemia, ${ }^{27}$ where development of ABT-263 has produced a potent agent, ABT-199, which avoids the problem of thrombocytopenia seen with earlier agents. ${ }^{43}$ We investigated the efficacy of the first high-affinity BCL2 inhibitor, ABT-737, and have demonstrated a BCR-ABL specific effect in ALL in vitro. Furthermore, ABT-737 appeared to be more potent than imatinib in this setting, suggesting that BCL2 inhibition has the potential to improve on current therapeutic regimens. In order to pre-clinically investigate the effect of potential therapies in ALL in a supportive microenvironment, we have developed a real-time murine xenograft model of patientderived BCR-ABL-positive ALL. ${ }^{24}$ Six weeks of treatment with ABT737 led to a significantly slower rate of leukaemic progression and associated prolonged survival compared with vehicle treated mice. The increase in dissemination of luciferase-expressing tumour cells following cessation of ABT-737 treatment suggests that even better outcomes could be achieved with on-going treatment. Furthermore, there was no effect on the heart in ABT737 treated mice (data not shown) or on BCL2 expression in cardiomyocytes in vitro (Supplementary Figure 7). These results demonstrate both the in vivo efficacy of $B C L 2$ inhibition in $B C R-A B L-p o s i t i v e ~ A L L$, as well as the potential for our approach in pre-clinical disease modelling.

Our data indicate a selective advantage for low miR-17 92 expression in primary BCR-ABL-positive ALL cells. Since these miRNAs regulate expression of $B C L 2$ and other apoptosis regulators, the data demonstrate the crucial balance between proliferative signals and apoptosis in BCR-ABL-positive ALL. Our results demonstrate that $B C R-A B L$ expression may result not only in a proliferative state, but also in one which is primed for apoptosis and therefore reliant on upregulation of BCL2. This makes therapeutic targeting of this key anti-apoptotic molecule a logical and attractive option and may provide a therapeutic window relative to normal tissues. Inhibition of $B C L 2$ and $B C R-A B L$ in BCR-ABL-positive ALL cells resulted in different kinetics of cell death, turn-over of $\mathrm{BCL} 2$ protein and induction of miR-17 92 expression. We found that ABT-737 treatment led to a decrease in BCL2 protein levels and an increase in miR-17 92 miRNA expression in a BCR-ABL-dependent manner, suggesting that BCL2 inhibition results in the perturbation of a complex signalling network. This apparent positive feedback loop may act to augment the effects of pharmacological BCL2 inhibition.

In summary, we have sought to identify potential therapeutic targets in BCR-ABL-positive ALL by validating targets of a miRNA cluster showing downregulated expression and important survival function in this disease. Having validated the anti-apoptotic protein BCL2 as a miR-17 92 target, we have demonstrated the direct control of $B C L 2$ expression by $\mathrm{miR} \sim 17$ and $\mathrm{miR} \sim 18$ family members by the canonical RNAi effector protein AGO2. Finally, we have demonstrated pre-clinical efficacy of the BCL2 inhibitor, ABT-737, both in an in vitro setting and using an in vivo model of human BCR-ABL-positive ALL. We suggest that BCL2 inhibition should be considered for early phase clinical testing in BCR-ABL-positive ALL as a new strategy either to improve current standard curative treatments or long-term disease control.

\section{CONFLICT OF INTEREST}

The authors declare no conflict of interest.

\section{ACKNOWLEDGEMENTS}

We thank Iris Dallmann for technical assistance. MS and ME acknowledge the HW \& J Hector-Stiftung. $\mathrm{OH}$ and JV received support from Cancer Research, UK (C27943/A12788) and the North of England Children's Cancer Research Fund. SB is funded by an MRC Clinical Research Training Fellowship (G0802259). The IVIS spectrum was funded by Welcome Trust grant 087961.

\section{REFERENCES}

1 Moorman AV, Harrison CJ, Buck GA, Richards SM, Secker-Walker LM, Martineau M et al. Karyotype is an independent prognostic factor in adult acute lymphoblastic leukemia (ALL): analysis of cytogenetic data from patients treated on the Medical Research Council (MRC) UKALLXII/Eastern Cooperative Oncology Group (ECOG) 2993 trial. Blood 2007; 109: 3189-3197.

2 Hoelzer D, Gokbuget N. Recent approaches in acute lymphoblastic leukemia in adults. Critical Rev Oncol/Hematol 2000; 36: 49-58.

3 Rives S, Estella J, Gomez P, Lopez-Duarte M, de Miguel PG, Verdeguer A et al. Intermediate dose of imatinib in combination with chemotherapy followed by allogeneic stem cell transplantation improves early outcome in paediatric Philadelphia chromosome-positive acute lymphoblastic leukaemia (ALL): results of the Spanish Cooperative Group SHOP studies ALL-94, ALL-99 and ALL-2005. BritJ Haematol 2011; 154: 600-611.

4 Schultz KR, Bowman WP, Aledo A, Slayton WB, Sather H, Devidas M et al. Improved early event-free survival with imatinib in Philadelphia chromosomepositive acute lymphoblastic leukemia: a children's oncology group study. J Clin Oncol 2009; 27: 5175-5181.

5 Mizuta S, Matsuo K, Yagasaki F, Yujiri T, Hatta Y, Kimura Y et al. Pre-transplant imatinib-based therapy improves the outcome of allogeneic hematopoietic stem cell transplantation for BCR-ABL-positive acute lymphoblastic leukemia. Leukemia 2011; 25: 41-47.

6 Ottmann OG, Wassmann B, Pfeifer H, Giagounidis A, Stelljes M, Duhrsen U et al. Imatinib compared with chemotherapy as front-line treatment of elderly patients with Philadelphia chromosome-positive acute lymphoblastic leukemia ( $\mathrm{Ph}+\mathrm{ALL})$. Cancer 2007; 109: 2068-2076.

7 Fielding AK, Rowe JM, Richards SM, Buck G, Moorman AV, Durrant IJ et al. Prospective outcome data on 267 unselected adult patients with Philadelphia chromosome-positive acute lymphoblastic leukemia confirms superiority of allogeneic transplantation over chemotherapy in the pre-imatinib era: results from the International ALL Trial MRC UKALLXII/ECOG2993. Blood 2009; 113: 4489-4496.

8 Wassmann B, Pfeifer H, Stadler M, Bornhauser M, Bug G, Scheuring UJ et al. Early molecular response to posttransplantation imatinib determines outcome in MRD + Philadelphia-positive acute lymphoblastic leukemia ( $\mathrm{Ph}+\mathrm{ALL}$ ). Blood 2005; 106: 458-463.

9 Ribera JM, Oriol A, Gonzalez M, Vidriales B, Brunet S, Esteve J et al. Concurrent intensive chemotherapy and imatinib before and after stem cell transplantation in newly diagnosed Philadelphia chromosome-positive acute lymphoblastic leukemia. Final results of the CSTIBESO2 trial. Haematologica 2010; 95: 87-95.

10 Bassan R, Rossi G, Pogliani EM, Di Bona E, Angelucci E, Cavattoni I et al. Chemotherapy-phased imatinib pulses improve long-term outcome of adult patients with Philadelphia chromosome-positive acute lymphoblastic leukemia: Northern Italy Leukemia Group protocol 09/00. J Clin Oncol 2010; 28: 3644-3652.

11 Ravandi F, O'Brien S, Thomas D, Faderl S, Jones D, Garris R et al. First report of phase 2 study of dasatinib with hyper-CVAD for the frontline treatment of patients with Philadelphia chromosome-positive $(\mathrm{Ph}+)$ acute lymphoblastic leukemia. Blood 2010; 116: 2070-2077.

12 Pfeifer $\mathrm{H}$, Lange $\mathrm{T}$, Wystub $\mathrm{S}$, Wassmann $\mathrm{B}$, Maier J, Binckebanck $\mathrm{A}$ et al. Prevalence and dynamics of bcr-abl kinase domain mutations during imatinib treatment differ in patients with newly diagnosed and recurrent bcr-abl positive acute lymphoblastic leukemia. Leukemia 2012; 26: 1475-1481.

13 Tanzer A, Stadler PF. Molecular evolution of a microRNA cluster. J Mol Biol 2004; 339: 327-335.

14 Ventura A, Young AG, Winslow MM, Lintault L, Meissner A, Erkeland SJ et al. Targeted deletion reveals essential and overlapping functions of the miR-17 through 92 family of miRNA clusters. Cell 2008; 132: 875-886.

15 Petrocca F, Visone $\mathrm{R}$, Onelli MR, Shah MH, Nicoloso MS, de Martino I et al. E2F1-regulated microRNAs impair TGFbeta-dependent cell-cycle arrest and apoptosis in gastric cancer. Cancer Cell 2008; 13: 272-286.

16 Volinia S, Calin GA, Liu CG, Ambs S, Cimmino A, Petrocca F et al. A microRNA expression signature of human solid tumors defines cancer gene targets. Proc Natl Acad Sci USA 2006; 103: 2257-2261.

17 Ota A, Tagawa H, Karnan S, Tsuzuki S, Karpas A, Kira S et al. Identification and characterization of a novel gene, C13orf25, as a target for 13q31-q32 amplification in malignant lymphoma. Cancer Res 2004; 64: 3087-3095.

$18 \mathrm{Mu}$ P, Han YC, Betel D, Yao E, Squatrito M, Ogrodowski P et al. Genetic dissection of the miR-17 92 cluster of microRNAs in Myc-induced B-cell lymphomas. Gene Dev 2009; 23: 2806-2811.

19 Xiao C, Srinivasan L, Calado DP, Patterson HC, Zhang B, Wang J et al. Lymphoproliferative disease and autoimmunity in mice with increased miR-17-92 expression in lymphocytes. Nat Immunol 2008; 9: 405-414.

20 Olive V, Bennett MJ, Walker JC, Ma C, Jiang I, Cordon-Cardo C et al. miR-19 is a key oncogenic component of mir-17-92. Gene Dev 2009; 23: 2839-2849. 
21 Venturini L, Battmer K, Castoldi M, Schultheis B, Hochhaus A, Muckenthaler MU et al. Expression of the miR-17-92 polycistron in chronic myeloid leukemia (CML) CD34+ cells. Blood 2007; 109: 4399-4405.

22 Zeiser J, Gerhard R, Just I, Pich A. Substrate specificity of clostridial glucosylating toxins and their function on colonocytes analyzed by proteomics techniques. J Proteome Res 2013; 12: 1604-1618.

23 Rehe K, Wilson K, Bomken S, Williamson D, Irving J, den Boer ML et al. Acute $B$ lymphoblastic leukaemia-propagating cells are present at high frequency in diverse lymphoblast populations. EMBO Mol Med 2013; 5: 38-51.

24 Bomken S, Buechler L, Rehe K, Ponthan F, Elder A, Blair H et al. Lentiviral marking of patient-derived acute lymphoblastic leukaemic cells allows in vivo tracking of disease progression. Leukemia 2013; 27: 718-721.

25 Klucher KM, Lopez DV, Daley GQ. Secondary mutation maintains the transformed state in BaF3 cells with inducible BCR/ABL expression. Blood 1998; 91: 3927-3934.

26 O'Donnell KA, Wentzel EA, Zeller KI, Dang CV, Mendell JT. c-Myc-regulated microRNAs modulate E2F1 expression. Nature 2005; 435: 839-843.

27 Roberts AW, Seymour JF, Brown JR, Wierda WG, Kipps TJ, Khaw SL et al. Substantial susceptibility of chronic lymphocytic leukemia to BCL2 inhibition: results of a phase I study of navitoclax in patients with relapsed or refractory disease. J Clin Oncol 2012; 30: 488-496.

28 Rudin CM, Hann CL, Garon EB, Ribeiro de Oliveira M, Bonomi PD, Camidge DR et al. Phase II study of single-agent navitoclax (ABT-263) and biomarker correlates in patients with relapsed small cell lung cancer. Clin Cancer Res 2012; 18: 3163-3169.

29 Miranda KC, Huynh T, Tay Y, Ang YS, Tam WL, Thomson AM et al. A pattern-based method for the identification of MicroRNA binding sites and their corresponding heteroduplexes. Cell 2006; 126: 1203-1217.

30 Lal A, Navarro F, Maher CA, Maliszewski LE, Yan N, O'Day E et al. miR-24 Inhibits cell proliferation by targeting E2F2, MYC, and other cell-cycle genes via binding to 'seedless' 3'UTR microRNA recognition elements. Mol Cell 2009; 35: 610-625.

31 Hammell M, Long D, Zhang L, Lee A, Carmack CS, Han M et al. mirWIP: microRNA target prediction based on microRNA-containing ribonucleoprotein-enriched transcripts. Nat Methods 2008; 5: 813-819.
32 Ritchie W, Flamant S, Rasko JE. mimiRNA: a microRNA expression profiler and classification resource designed to identify functional correlations between microRNAs and their targets. Bioinformatics 2010; 26: 223-227.

33 Scherr M, Venturini L, Battmer K, Schaller-Schoenitz M, Schaefer D, Dallmann I et al. Lentivirus-mediated antagomir expression for specific inhibition of miRNA function. Nucleic Acids Res 2007; 35: e149.

34 Cory S, Huang DC, Adams JM. The Bcl-2 family: roles in cell survival and oncogenesis. Oncogene 2003; 22: 8590-8607.

35 Strasser A. The role of $\mathrm{BH} 3$-only proteins in the immune system. Nat Rev Immunol 2005; 5: 189-200.

36 Sanchez-Garcia I, Grutz G. Tumorigenic activity of the BCR-ABL oncogenes is mediated by BCL2. Proc Natl Acad Sci USA 1995; 92: 5287-5291.

37 Oltersdorf T, Elmore SW, Shoemaker AR, Armstrong RC, Augeri DJ, Belli BA et al. An inhibitor of $\mathrm{Bcl}-2$ family proteins induces regression of solid tumours. Nature 2005; 435: 677-681.

38 Tse C, Shoemaker AR, Adickes J, Anderson MG, Chen J, Jin S et al. ABT-263: a potent and orally bioavailable Bcl-2 family inhibitor. Cancer Res 2008; 68: 3421-3428.

39 Walensky LD. From mitochondrial biology to magic bullet: navitoclax disarms BCL-2 in chronic lymphocytic leukemia. J Clin Oncol 2012; 30: 554-557.

40 Gandhi L, Camidge DR, Ribeiro de Oliveira M, Bonomi P, Gandara D, Khaira D et al. Phase I study of Navitoclax (ABT-263), a novel Bcl-2 family inhibitor, in patients with small-cell lung cancer and other solid tumors. J Clin Oncol 2011; 29: 909-916.

41 Bodet L, Gomez-Bougie P, Touzeau C, Dousset C, Descamps G, Maiga S et al. ABT-737 is highly effective against molecular subgroups of multiple myeloma. Blood 2011; 118: 3901-3910.

42 Wilson WH, O'Connor OA, Czuczman MS, LaCasce AS, Gerecitano JF, Leonard JP et al. Navitoclax, a targeted high-affinity inhibitor of BCL-2, in lymphoid malignancies: a phase 1 dose-escalation study of safety, pharmacokinetics, pharmacodynamics and antitumour activity. The Lancet Oncol 2010; 11: 1149-1159.

43 Souers AJ, Leverson JD, Boghaert ER, Ackler SL, Catron ND, Chen J et al. ABT-199, a potent and selective BCL-2 inhibitor, achieves antitumor activity while sparing platelets. Nat Med 2013; 19: 202-208.

(c) (i) This work is licensed under a Creative Commons Attribution 3.0 creativecommons.org/licenses/by/3.0/

Supplementary Information accompanies this paper on the Leukemia website (http://www.nature.com/leu) 